\title{
COMPARATIVES STUDY OF NON-TRADITIONAL HOLE MACHINING PROCESSES
}

\author{
Sanjay Mishra ${ }^{1}$ \\ I.T.S Engineering College, Greater Noida, India \\ dr.sanjaymishra@its.edu.in
}

\author{
Rajesh Kumar Porwal $^{2}$ \\ KCC Institute of Technology and Management, \\ Greater Noida, India
}

\begin{abstract}
Recent advances in microfabrication are characterized by a progressive miniaturization leading towards higher integration. The fabrication of precise hole in different materials is one of the most challenging tasks in manufacturing industry. Since holes are prepared in the end product therefore the rejection of product due to poor hole quality is not acceptable in modern manufacturing processes. In this study, a detailed analysis of different hole making techniques has been elaborated so that a manufacturing engineer can get a broad guideline regarding the merits and demerits of different hole making processes.
\end{abstract}

Keywords_Laser Beam drilling; drilling ECM; drilling USM; sinking EDM

\section{INTRODUCTION}

A depression type of feature created in a solid workpiece is called hole when depth-to- diameter ratio is greater than 5:1 [1]. Depending on diameter, hole can be classified as large $(>1$ $\mathrm{mm}$ ) or small hole $(<1 \mathrm{~mm})$. Holes may be blind or through and depending on orientation it may be termed as horizontal, vertical or inclined. Holes can be created using both conventional machining methods and unconventional machining methods. Mechanical drilling is the most widely used conventional machining method to create hole in a workpiece by forcing a rotating twist drill against it with the help of a drill press. The advent of split, crankshaft and spiral point drills has further enhanced its applicability in modern industries like aircraft and automotive industries [2]. Moreover, the introduction of new technique like peck-drilling has made it feasible to use mechanical drilling for creation of large number of small diameter holes in printed circuit board (PCB) used in electronic industries [3].

Creation of quality hole by machining method has always been a challenge to manufacturing engineers because of inaccuracies involved during production of these holes. Advances in the field of aviation, automobile, medical devices, communications, optics, electronics and computers have created a need for holes of different shape and sizes. The complexity and degree of integration required for these applications needs a creation of hole with minimum hole taper without mechanical and thermal distortion. To enhance the functional capability of products, a continuous endeavor is being made to develop products made of high characteristics materials such as superalloys, ceramics and composites. In order to enhance the efficiency, the technologically advanced industries like aerospace, nuclear reactors, automobiles etc. often requires components made of these materials with a large number of geometrically accurate holes. Poor hole quality accounts for nearly $60 \%$ of part rejection in modern manufacturing industries. Since hole is produced in finished part, therefore the economical impact of this rejection is very high [4]. The conventional method of hole creation produce certain machining defects which may lead to reduction of strength and fatigue life of components. Moreover, it may also generate micro-crack at the inner surface of the hole and in case of composite materials it may also lead to delamination [5]. Therefore, the conventional machining methods cannot be used for creation of holes in these materials in acceptable tolerance limits because of improved mechanical properties [6, 7].

The cost effective production of holes with stringent design requirement (high precision, complex shapes and high surface integrity) and tight geometrical tolerance in difficultto- machine materials have always been a challenging task for manufacturing engineers [8]. Therefore, non-traditional machining techniques which remove the excess material by utilizing various forms of innovative energy such as thermal energy of electric spark or energy beam, chemical energy of electrolysis or etching and mechanical energy of ultrasonic vibration or kinetic jets are used for creating holes in these materials. Several nontraditional machining processes such as, Electro-Discharge Machining (EDM), Laser Beam Machining (LBM), Electron Beam Machining (EBM), Ion Beam Machining (IBM), Electro-Chemical Machining (ECM), Chemical Machining (CHM), Ultrasonic Machining (USM), Abrasive Water Jet Machining (AWJM), and Abrasive Air Jet Machining (AAJM) as shown in Fig. 1 are used for creating symmetrical as well as non-symmetrical holes in such materials. A brief description about some of these nontraditional hole drilling methods is given below.

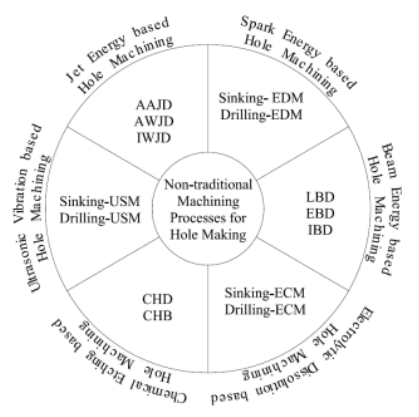

Fig. 1 Non-traditional machining processes for hole making 


\section{NONTRADITIONAL HOLE MACHINING PROCESSES}

A. Electro-Discharge Machining (EDM) is a spark energy based hole machining method to create small holes, blind holes and deep holes in electrically conductive material without being affected by its hardness. EDM drilling uses a tubular tool electrode where the dielectric is flushed down the interior hole of the tube in order to remove the machining debris. It can produce irregular, tapered, curved as well as inclined holes of diameter 0.1 to $0.5 \mathrm{~mm}$ diameters with an overcut of 0.01 to $0.05 \mathrm{~mm}$. EDM drilling is widely used for creating cooling channels in turbine blades made of hard superalloys. Micro-EDM is accepted as an efficient method for the fabrication of precise hole upto a diameter of $5 \mu \mathrm{m}$. The merits of EDM technique becomes more apparent during machining of Metal Matrix Composites (MMCs) which has the highest hardness in reinforcement [9]. A different variation of EDM process known as EDM fast hole drilling was demonstrated by Yilmaz and Okka [10] where high flush pressure is delivered using a constantly rotated hollow electrode to create hole size between 0.15 and $3 \mathrm{~mm}$ with a depth-to-diameter ratio of 150:1 at drilling rate of $1 \mathrm{~mm} / \mathrm{s}$.

B. Laser Beam Drilling ( $L B D$ ) highly coherent beam of electromagnetic radiation is focused to very small diameter in order to produce high power density to remove a small portion of workpiece by melting or vaporization. Holes upto $250 \mu \mathrm{m}$ diameter can be easily drilled with dimensional accuracy of \pm $0.025 \mathrm{~mm}$ [11].

C. Electron Beam Drilling ( $E B D)$ uses a focused beam of high velocity electrons to remove the material. The stream of electrons strikes a workpiece and causes rapid melting and vaporization of the material. It is used for the precision drilling of holes (0.1-1.0 mm diameter) in a variety of materials. Drilling rates of up to 4000 holes per second can be achieved and no difficulty is encountered with acute angles. EBD can be successfully used to create deep cylindrical, conical and barrel-shaped hole with constant accuracy and repeatability in advanced engineering materials. The process features no mechanical distortion and the diametral tolerance of \pm 0.025 $\mathrm{mm}$ with an aspect ratio of $25: 1$ can be achieved by this method [9].

D. Ion Beam Drilling (IBD) takes place in a vacuum chamber using charged ions fired from an ion source toward the workpiece by mean of accelerating voltage. Here, the material is removed by transfer of momentum from the incident ions to the atoms, in the surface of the material. A heated tungsten filament acts as the cathode from which electrons are accelerated by means of high voltage towards the workpiece. It can produce hole with a surface finish of less than $1 \mu \mathrm{m}$ having an accuracy and repeatability of \pm 1 percent [11].

E. Electro-Chemical Drilling (ECD) is a controlled rapid electrolytic dissolution process using tubular shaped electrode made of brass, copper or stainless steel. The electrolytes solution $\left(\mathrm{NaCl}, \mathrm{NaNO}_{3}, \mathrm{NaClO}_{3}\right)$ flows through the narrow gap between the two electrodes due to which the anodic material (workpiece) dissolves locally. The major limitations of ECD process are the failure of the tool insulation and production of an overcut hole. It can produce holes of diameter 1 to $20 \mathrm{~mm}$ with an aspect ratio of 20:1. [11]. ECD can produce hole having a surface finish of 0.1-1.5 $\mu \mathrm{m}$, geometrical tolerance of $\pm 0.012 \mathrm{~mm}$ with a hole taper of $0.025 \mathrm{~mm} / \mathrm{mm}$ [8].

F. Shaped Tube Electrolytic Machining (STEM) is a modified ECD process which uses acid electrolyte to avoid the formation of insoluble precipitates during machining. It produces hole with large depth-to-diameter ratio. Holes are produced by controlled depletion of an electrically conductive material. The tool (cathode) is made of acid resistant material such as titanium. It is suitable for multiple hole drilling of either different or the same sized holes. It produces holes with uniform wall thickness in repetitive production. The moleculeby-molecule dissolution of the material produces high integrity holes without any residual stress. STEM can be used to fabricate large shaped elliptical and rectangular holes and holes with contoured surfaces [12]. Holes of diameter 0.5-6 $\mathrm{mm}$ with an aspect ratio of 150 can be produced without formation of heat-affected zone and recast layer.

G. Capillary Drilling $(C D)$ is used to drill holes that are deep enough to be drilled by EDM and too small to be drilled by STEM. The drill tube is a glass capillary (smaller than the required diameter) through which electrolyte flows under pressure and the cathode is a platinum wire. CD can be successfully used to drill small diameter (0.127-1.27 mm) holes with an aspect ratio of 50:1 and diametral tolerance of \pm $0.05 \mathrm{~mm}$ in superalloys [1]. The process is suitable only for corrosion resistant metals and it cannot be used to create holes at an angle to the surface [11].

$H$. Ultrasonic Drilling (USD) is employed to create drill in hard and brittle materials (both electrically conductive and non-conductive). The high-frequency vibrations $(18-20 \mathrm{kHz})$ delivered to a tool tip, embedded in abrasive slurry (boron carbide or silicon carbide), by a booster or sonotrode is used to create accurate hole in the workpiece. Since this method is non-thermal, non-electrical, and non-chemical, it produces virtually stress-free holes even in the hard and brittle materials [11]. USD can be used to create small diameter holes (0.4-1 $\mathrm{mm}$ ) in hard materials (glass, alumina, ceramics, sapphire and composite materials) upto a depth of $5 \mathrm{~mm}$ with a conicity of approximately 0.2 degree and roundness error of $20-140 \mu \mathrm{m}$ $[9,13]$.

I. Abrasive Air Jet Drilling (AAJD), Abrasive Water Jet Drilling (AWJD) and Ice Water Jet Drilling (IWJD) are the jet energy based hole machining methods using the pneumatic pressure or hydraulic pressure as the energy source for creating hole. In AAJD, air driven abrasive particles (10-40 $\mu \mathrm{m})$ jet strikes the workpiece at high velocity $(150$ to $300 \mathrm{~m} / \mathrm{s})$ to remove the material. It can create small diameter holes (upto $1.5 \mathrm{~mm}$ thick steel plate and $6.5 \mathrm{~mm}$ thick glass) with a diametrical tolerance of $\pm 0.05 \mathrm{~mm}$ and surface roughness of 0.15-1.5 $\mu \mathrm{m}$ depending on size of abrasive grain particles $[8,11]$. It is widely used for drilling glass wafers. AWJD uses jet consisting of water and abrasive particles of size 10 to 150 $\mu \mathrm{m}$ in the ratio of 70:30 to remove material. It can be used to drill thicker workpiece as compare to AAJD without any thermal or mechanical damage. AWJD is more suitable for 
creating holes in glass, ceramics and composites with a repeatability of $\pm 0.04 \mathrm{~mm}$. The produced hole has a surface roughness of 3.8 to $6.4 \mu \mathrm{m}$ with a tolerance of $\pm 0.13 \mathrm{~mm}$. In IWJD the abrasive particles are replace by ice particles (500 $\mu \mathrm{m})$ to form ice jet. It can be advantageously used in electronic, medical and space industries [11].

\section{A. Maintaining the Integrity of the Specifications}

The template is used to format your paper and style the text. All margins, column widths, line spaces, and text fonts are prescribed; please do not alter them. You may note peculiarities. For example, the head margin in this template measures proportionately more than is customary. This measurement and others are deliberate, using specifications that anticipate your paper as one part of the entire proceedings, and not as an independent document. Please do not revise any of the current designations.

\section{ENERGY BEAMS FOR HOLE MAKING}

Beam processing of materials utilizes the thermal energy of a particular beam for localized controlled removal of material from the workpiece. Depending upon the nature of beam, these processes can be categorized into three segments: Electron Beam Machining (EBM), Ion Beam Machining (IBM) and Laser Beam Machining (LBM).

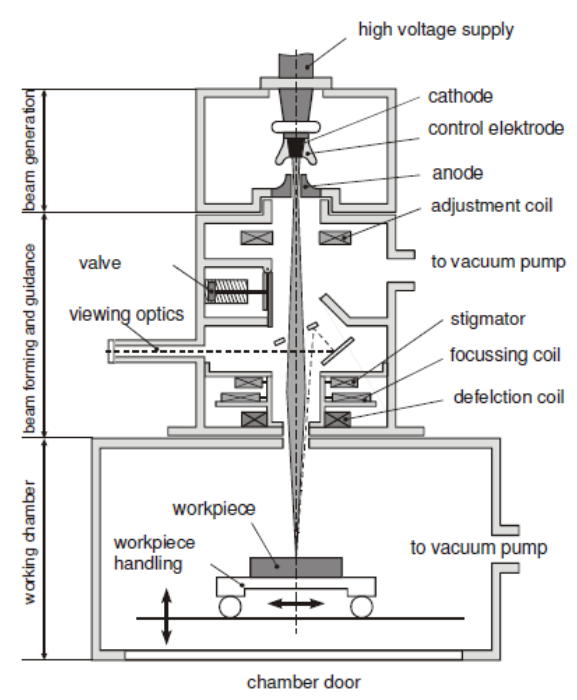

Fig. 2 Schematic of Electron Beam Machining [17]

In $E B M$, the kinetic energy of high velocity stream of electrons is converted into thermal energy on impinging the work surface to instantly vaporize the material [Fig. 2]. Thus, it can also be defined as a precisely controlled vaporization process. The EBM can be used to create extremely small diameter holes (25-125 $\mu \mathrm{m}$ diameters) with very high aspect ratios (more than 100:1) in thin sheet upto $1.25 \mathrm{~mm}$. When the diameter of required hole is larger than beam diameter, the beam can be deflected in a circular path with proper radius. EBM produces hole taper of $2^{\circ}-4^{\circ}$ when the sheet thickness is more than $0.1 \mathrm{~mm}[11]$.
$I B M$ is a molecular manufacturing process based on the sputtering off phenomenon of materials. As shown in Fig. 3, material is removed due to bombardment of energized ions of $1-10 \mathrm{keV}$ and current density of $1 \mathrm{~mA} / \mathrm{cm}^{2}$. It is the ideal process for nano-finishing of high melting point and hard brittle materials such as ceramics, semiconductors, diamond etc. As there is no load on the workpiece while finishing, therefore it is also suitable for finishing of very thin object, optics and soft material [18].

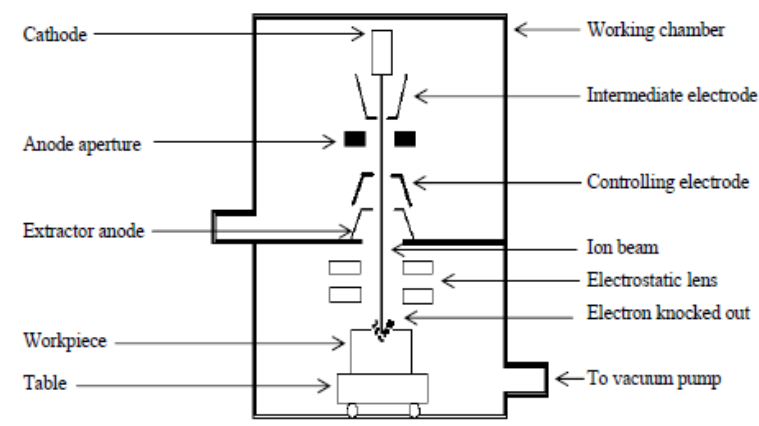

Fig. 3 Schematic of Ion Beam Machining [11]

Laser beam are most widely used beam for material processing due to broad range of tasks that can be performs for a wide variety of materials [Fig.4]. It provides the advantage of high processing speeds, low thermal effect on workpiece, and easy automation. Laser can be used for creating holes in different ways like single pulse drilling, percussion drilling, trepanning drilling, and helical drilling [18].

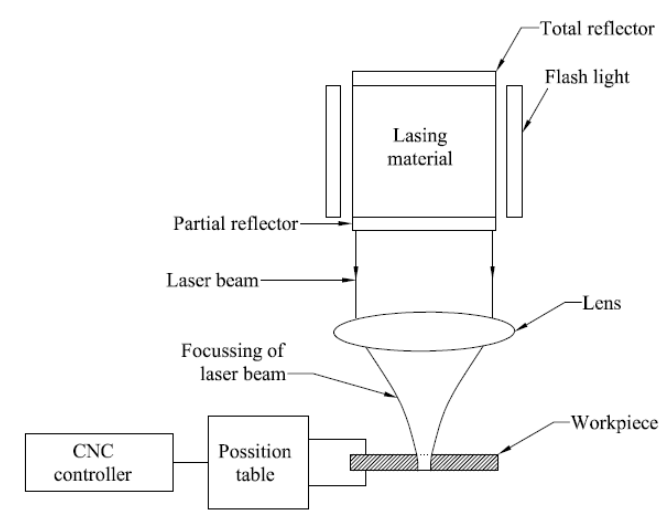

Fig. 4 Schematic of Laser Beam Machining

\section{PROCESS CAPABILITIES OF HOLE MAKING PROCESSES}

The hole quality produced by LBPD competes with EDM for hole diameters below $1 \mathrm{~mm}$ and for depths less than $15 \mathrm{~mm}$ whereas it compete with ECM when cavities of small diameter are required. USD is suitable for small diameter holes $(0.4-1 \mathrm{~mm})$ in hard materials with depth upto $5 \mathrm{~mm}$. IBM and EBM are more suitable for creating holes in semiconductor materials [13]. 
Table 1 Process capabilities of non-traditional hole machining methods [13]

\begin{tabular}{|c|c|c|c|c|c|c|}
\hline Parameters & $\begin{array}{l}\text { Drilling- } \\
\text { EDM }\end{array}$ & LBD & $\begin{array}{l}\text { Drilling } \\
\text {-ECM }\end{array}$ & $\begin{array}{l}\text { Drilling- } \\
\text { USM }\end{array}$ & AAJD & AWJD \\
\hline $\begin{array}{l}\text { Minimum } \\
\text { hole } \\
\text { diameter }\end{array}$ & 50 & 20 & 750 & 75 & 400 & 750 \\
\hline $\begin{array}{l}\text { Hole } \\
\text { tolerance } \\
(\mu \mathrm{m})\end{array}$ & \pm 25 & $\begin{array}{l} \pm 50- \\
200\end{array}$ & \pm 25 & \pm 25 & \pm 120 & \pm 0.13 \\
\hline $\begin{array}{l}\text { Minimum } \\
\text { surface } \\
\text { roughness } \\
(\mu \mathrm{m})\end{array}$ & 6 & 20 & 2 & $16-32$ & $0.15-1.5$ & $3.8-6.4$ \\
\hline Aspect ratio & $20: 1$ & $75: 1$ & $20: 1$ & $10: 1$ & $40: 1$ & $40: 1$ \\
\hline
\end{tabular}

Table 2 Application of non-traditional hole making methods [14]

\begin{tabular}{|l|c|}
\hline \multicolumn{1}{|c|}{ Hole characteristics } & Non-traditional hole \\
\hline Very small hole diameter $(0.025-0.125 \mathrm{~mm})$ & EBM, LBM \\
\hline Holes with large depth-to-diameter ratio (> 20) & ECM , EDM \\
\hline Non-circular holes & EDM , ECM \\
\hline
\end{tabular}

\section{CONCLUSIONS}

The above survey gives us brief information about the various non-traditional hole machining process. The Abrasive Air Jet Drilling can be used for producing holes with minimum surface roughness while Laser Beam Drilling techniques can be used for fabrication of very small holes with high aspect ratio. EDM and ECM can be used for producing non circular holes. A concise knowledge about the various processes can be acquired through this study which can be useful to selecting the process according to its application size.

\section{References}

[1] G Kalpakjian, S. and Schmid, S.R., Manufacturing Engineering and Technology, 4th Edition, Pearson Education, New Delhi, 2004.

[2] Hocheng, H. and Tsao, C.C., Effects of special drill bits on drilling induced delamination of composite materials, International Journal of Machine Tools and Manufacture, 46 (2006) 1403-1416.

[3] Kim, D.W., Lee, Y.S., Park, M.S. and Chu, C.N., Tool life improvement by peck drilling and thrust force monitoring during deep-micro-hole drilling of steel, International Journal of Machine Tools and Manufacture, 49 (2009) 246-255.

[4] Krishnaraj, V., Prabukarthi, A., Ramanathan, A., Elanghovan, N., Kumar, M.S., Zitoune, R. and Davim, J.P., Optimization of machining parameters at high speed drilling of carbon fiber reinforced plastics (CFRP) laminates, Composites: Part B,43 (2012) 1791-1799.

[5] Abel, A. and Heilmann, M., Deep hole drilling using tools with small diameters-Process analysis and process design, CIRP AnnalsManufacturing Technology, 61(2012) 111-114.
Fenoughty, K.A., Jawaid, A. and Pashby, I.R., Machining of advanced engineering materials using traditional and laser techniques, Journal of Materials Processing Technology, 42(1994) 391-400.

Mustafa, A., Caydas, U. and Haschak, A., Optimization of microEDM drilling of Inconel 718 superalloy, International Journal of Advanced Manufacturing Technology, DOI 10.1007/s00170-0124385-8.

Jain, V. K., Advanced Machining Processes, Allied Publishers Private Limited, New Delhi, 2008.

Benedict, G.F., Nontraditional Manufacturing Processes, Taylor \& Francis, New York, 1987.

Yilmaz, O. and Okka, M.A., Effect of single and multi-channel electrodes application of EDM fast hole drilling performance, International Journal of Advanced Manufacturing Technology, DOI 10.1007/s00170-010-2625-3.

El-Hofy, H., Advanced Machining Processes, Mc Graw Hill, New York, 2005.

Sen, M. and Shan, H.S., A review of electrochemical macro-to microhole drilling processes, International Journal of Machine Tools and Manufacture, 45(2005), 137-152.

Ion, J.C., Laser Processing of Engineering Materials, Elsevier, Oxford, 2005.

Groover, M.P., Fundamentals of Modern Manufacturing, Willey India, New Delhi, 2002.

Zhang, H., Xu, J. and Wang, J., Investigation of novel hybrid process of laser drilling assisted with jet electrochemical machining, Optics and Lasers in Engineering, 47 (2009) 1242-1249.

Tsai, C.H. and Li, C.C., Investigation of underwater laser drilling for brittle substrates, Journal of Materials Processing Technology, 209 (2009) 2838-2846.

Moarrefzadeh, A., Finite element simulation of electron beam machining (EBM) process, International Journal of Multidisciplinary Sciences and Engineering, 2 (2011) 51-56.

Majumdar, J. D. and Manna, I., Laser processing of materials, Sadhana, 28 (2003) 495-562. 